\title{
The world this week
}

\section{Newsinfocus}

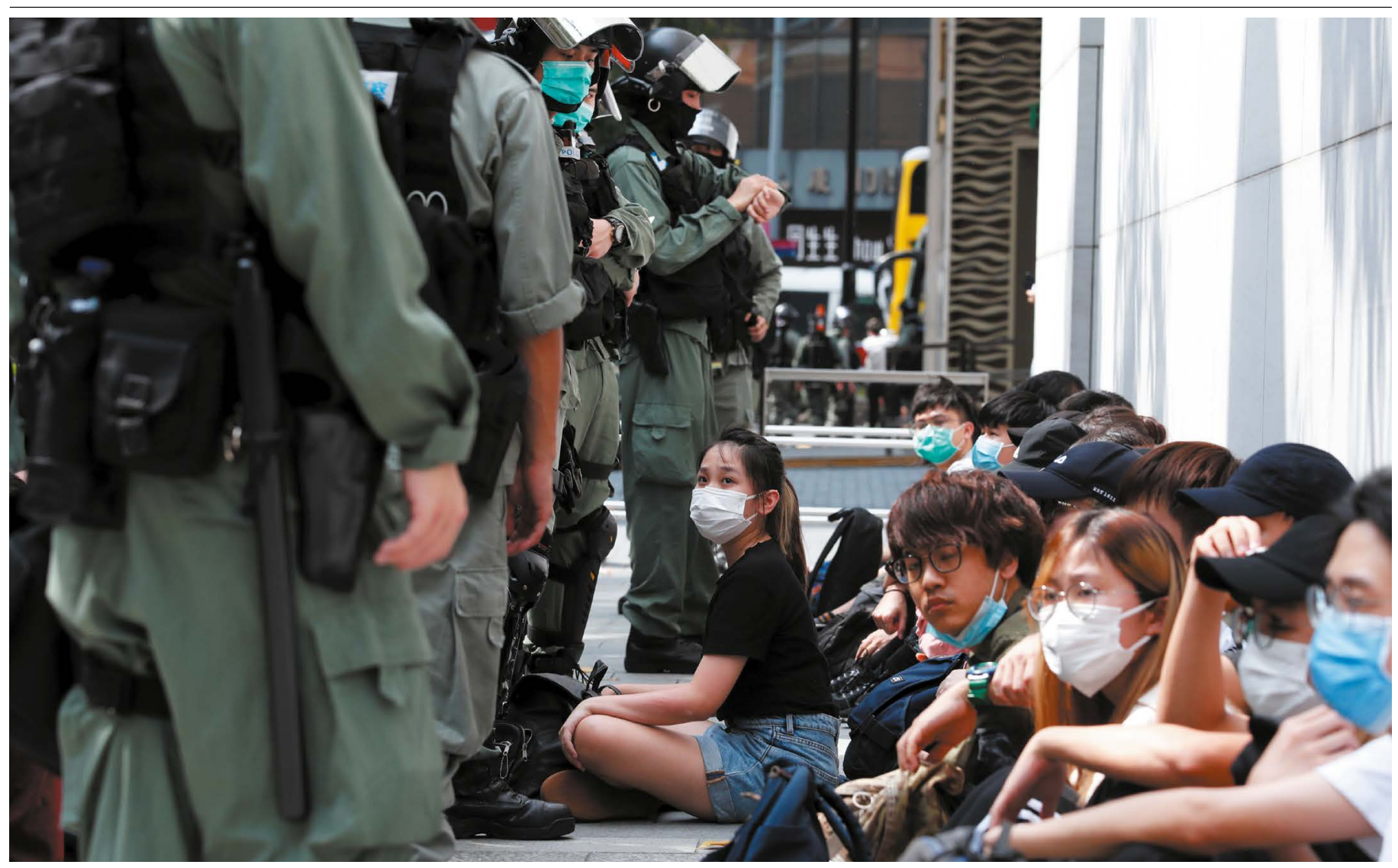

There have been ongoing protests in Hong Kong for the past year.

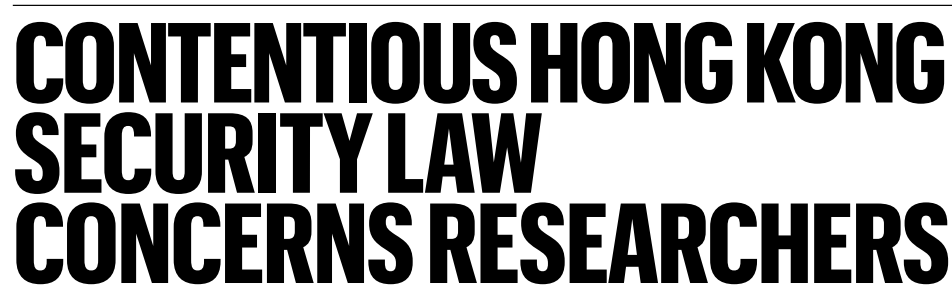

Some fear that the planned Chinese bill could harm research freedom and collaboration, but others are confident it won't affect research.

\section{By Andrew Silver}

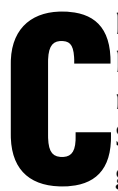

hina's plan to introduce a new security law in Hong Kong has prompted mixed reactions from scientists there. Some fear that such a law could lead to government interference in research, restrict participation in international collaborations and increase self-censorship, whereas others are confident that research will be unaffected.

On 28 May, China's parliament approved plans to bypass Hong Kong's local legislature to enact a national security law in the city that will criminalize subversion, secession, foreign interference and terrorism. The new law hasn't yet been drafted, but could come into effect in the next month, according to Chinese state media.

China's central government and Hong Kong chief executive Carrie Lam say that the national security law - something many countries have - is meant to promote a safe society. But foreign governments, including those of the United States, the United Kingdom, Canada and Australia, say that it breaches the 1984 agreement between Britain and China to protect the city's autonomy until 2047. As a result of the new law, US President Donald Trump said on 29 May that he will take steps to end the special treatment that the United States gives Hong Kong, such as the exemption from tariffs that are imposed on goods imported from mainland China.

The security legislation follows a year marked by massive street protests, which started in June 2019 when Hong Kong's government proposed a law that would have legalized the extradition of people from the city to mainland China to stand trial or serve criminal sentences. The bill was later withdrawn, but protests continued - among them, violent clashes between students and police on several university campuses. Smaller street protests still happen regularly, and 
government officials have said that one aim of the new security law is to stop them.

Because the security law hasn't yet been drafted, it is not clear how it will be implemented or how it might affect researchers' lives.

The heads of the governing councils of Hong Kong's eight publicly funded universities have expressed support for the new bill, and say universities will be able to continue research and learning once it is introduced. In a 1June statement, they said: "As residents of Hong Kong, we enjoy the protection provided by the state, and in turn have a reciprocal obligation to protect the state by supporting the introduction of legislation which prohibits criminal acts that threaten the existence of the state."

But some academics are concerned that the law could allow the central government to interfere with independent research in the name of national security. "Academics in Hong Kong are very concerned about possible changes," says an administrator at a university in Hong Kong who requested anonymity because they think their university is under pressure to publicly support the security law. They worry that a national security law could be used to restrict the publication of sensitive research, such as studies on the new coronavirus. Scientists on the mainland need government approval to publish research relating to the origins of the pandemic.

A Hong Kong-based editorial-board member for a scientific journal who also requested anonymity because they need permission to speak to the press, says they are worried that foreign research grants or international collaborations - particularly with the United States - could be defined as foreign interference and restricted under the law.

When asked about researchers' concerns, Hong Kong's Education Bureau noted that the laws that safeguard academic freedom and institutions' autonomy will remain. "It is counterproductive and not conducive to the pursuit of academic excellence by Hong Kong's universities to demonize the National Security legislation and to create unfounded and unnecessary fear in the academic circle," the bureau said in an e-mail to Nature.

\section{Risk of self-censorship}

Some academics think that one of the greatest effects the new law will have on research will be an increase in self-censorship. Researchers are already wary about making comments or publishing research that could upset the central government - work that could distress financial markets, for example, such as negative results from a large vaccine trial, says Shekhar Madhukar Kumta, an assistant dean of education for the medical faculty at the Chinese University of Hong Kong. Under the new law, even more researchers are likely to be worried about this, whether or not they're at risk of breaking the law, he says.

A foreign researcher who studies science and ethics at a university in Hong Kong, who requested anonymity for fear their comments could jeopardize their work visa, says they no longer feel able to criticize the science and technology practices of the central

\section{"Academics in Hong Kong are very concerned about possible changes."}

government while living in Hong Kong. They worry that the security law could bring the risk of prison sentences for such criticisms. "Even science can be politicized," they say.

Another researcher, Natalie Wai-man Wong, a visiting environmental researcher at the City University of Hong Kong, says she doesn't think her research on environment management and governance in mainland China, Hong Kong and Taiwan is particularly sensitive. But she has decided that she will do less work focusing on mainland China - and work on existing data sets, rather than generating her own - to avoid the risk of her work being classified as subversive under the security law. "This is what I can do at this moment," she says. Wong doesn't view the changes she's making as bad, but, rather, as an opportunity to meet new collaborators and learn new things.

\section{No need to worry}

Other researchers who spoke to Nature don't see any evidence that the law will affect research. Matthew Evans, dean of science at the University of Hong Kong, says he's seen no indication that publishing research on politically sensitive topics or participating in international projects and grants will be restricted under the law.

One thing that Evans does think could affect science in Hong Kong is the US government's announcement of its intent to remove the city's special policy status, which includes access to sensitive data. That could affect the ability of scientists in Hong Kong to access US research data from institutions such as NASA, he says.

\section{ASTRONOMERSSPOT FIRSTFASTRADIOBURST INTHEMILKYWAY}

\section{The burst came from a nearby star - and provides a close-up view of one of astronomy's biggest puzzles.}

\section{By Alexandra Witze}

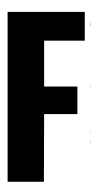
or a fraction of a second in late April, a hyper-magnetized star in the Milky Way blasted out radio energy. Now scientists say that this sudden, strange blip could help to explain one of astronomy's biggest puzzles: what powers the hundreds of other mysterious fast radio bursts (FRBs) that have been spotted much farther away in the Universe.

The event is the first fast radio burst - brief, powerful cosmic flashes that flare for milliseconds - to be detected in the Milky Way.

The star it came from, called SGR 1935+2154, is a magnetar - a dense, spinning ember left behind after a supernova, wrapped in intense magnetic fields. Many astronomers think that fast radio bursts come from magnetars, but haven't been able to show the link.

“I wouldn't say it's the nail in the coffin that we've figured out that fast radio bursts come from magnetars," says Emily Petroff, an astronomer at the University of Amsterdam in the Netherlands. "But it's by far the most promising piece of evidence that we've found."

Preliminary papers describing the burst have flooded the arXiv preprint server.

Until now, the closest known fast radio burst happened around 150 parsecs (490 million light years) from Earth. This magnetar is in our Galaxy just 10,000 parsecs away, making it close enough for astronomers to have a great view as it sizzles with activity. "Here is something that gets close to the insane intensity of cosmic FRBs, but that is happening not so far away," says Sarah Burke Spolaor, an astronomer at West Virginia University in Morgantown. “It's a fantastic opportunity to learn about at least one of the sources that could be causing FRBs."

\section{Cake-tin telescope}

The show began on 27 April, when satellites including NASA's Neil Gehrels Swift Observatory spotted $\gamma$-rays streaming from SGR 1935+2154. The star is one of about 30 known magnetars in the Milky Way; these occasionally go through spurts of activity during which they emit 